\title{
New skills for a new century? Challenging the orthodoxy: the role of Citizenship and Enterprise Education in promoting effective learning.
}

\author{
Jacek Brant \\ Institute of Education \\ Jenny Wales \\ The Nuffield Foundation
}

Citizenship and enterprise education are now compulsory in the English school curriculum; both offer challenges and opportunities for the development of effective learning. There is a long-standing problem of definition with enterprise education. One sees enterprise as teaching entrepreneurship, another sees it as more generic project development, and a final conceptualisation is the development of personal 'enterprising' dispositions, such as creativity, problem solving, and flexibility. These definitions have drastically different implications for teaching and the organisation of the curriculum. If the purpose of enterprise education is to prepare students to start businesses then enterprise education ought to develop the knowledge, understanding and skills that are relevant for running a company. In that case the link between enterprise education and business studies is close. However, if the purpose of enterprise education is to develop students' capacity to take the initiative in any situation, this could arguably be created in any part of the curriculum. Citizenship has more in common with the third definition of enterprise. While offering a body of knowledge, it also aims to develop skills and attitudes which can influence not only the individual student but the culture of the schools thus enhancing student's experiences and possibly attainment.

\section{Introduction}

It is perhaps pertinent to begin this paper by considering the purpose of education in general and of schools in particular. Perhaps the most obvious tension lies between the idealistic notion of education 'for its own sake' and the more pragmatic notion of schooling for a particular purpose, for example for the needs of industry. It is beyond the scope of this paper to enter into such a philosophical debate, but when one considers the government's motives in promoting both citizenship and enterprise education in recent years it is important to raise the issue. We refer the reader to Dewey (1938) who had strongly developed views on the matter. He argued for a democratic school where children had an active part to play in its running. He also believed in vocational education and wanted the school's curriculum to be relevant for the needs of industry. In terms of pedagogy, he recommended student-centred learning with an emphasis on discovery learning. We argue that seventy years on, his ideas are still of relevance today.

A defining moment in English [1] educational policy came in 1976 when the Prime Minister, James Callaghan, delivered the now famous Ruskin speech at Oxford University. In this speech he strongly criticised the way in which education had become a 'secret garden' in which teachers and other educational professionals had freedom to decide what to teach and how to teach it. In 1976 there was no National Curriculum, no parental choice for parents sending their children to state schools in England and there were no league tables. The speech stimulated public debate which helped generate a political climate in 
which it was seen as desirable for the government to take a proactive role in shaping what was taught in schools. In succeeding years the British government increasingly assumed the right to determine on behalf of industry and parents what should happen in schools.

There were economic arguments for state intervention in education. The high unemployment of the 1980s injected a sense of urgency into government efforts to 'improve education' for education came to be seen as a way of increasing the supply of suitably qualified workers for the benefit of industry. From the 1990s it has been a belief that increased global competition meant that UK workers needed to be more highly educated to compete in the era of 'globalisation'.

The arguments for a statutory core curriculum had been strongly advanced by HMI [2] in the 1980s. One argument was philosophical. Education should be thought of as equipping young people for each of the areas of experience which make up adult life. Therefore they should not be permitted to specialise in their education to the extent that they miss out one of these areas by, for example, learning no science, no artistic subject or no modern foreign language beyond the age of 14. A second argument was bureaucratic. When children move from one school to another during their secondary years their education should not be disrupted by moving from one type of curriculum to another.

There has also been a renewed government interest in England in recent years in the 'cross-curricular themes' that disappeared with little trace in the early 1990s. Two of the cross-curricular themes were 'Citizenship Education' and 'Economic and Industrial Understanding'. From September 2002 all schools in England have been required to teach 'Citizenship Education' and this has been backed by a required programme of study and a statement of expected learning outcomes. Schools are also to be required to make more systematic provision for enterprise education following the publication of the Howard Davies Review (Davies, 2002). 'The Government shares the assessment of the Davies review of enterprise and the economy in education, which reported that effort to build a deeper and wider entrepreneurial culture must begin in schools' (DfES, 2004).

It now appears likely that these initiatives will make a deeper impact on the school curriculum than was achieved through the cross-curricular initiatives in the 1980s and early 1990s. It is fascinating to note that the government has taken the opposite approach to curriculum development to the one employed in the development of the National Curriculum in England. The National Curriculum was developed by central planning which identified what should be taught and how learning should be assessed. But the approach to curriculum development in Citizenship and Enterprise Education adds up to saying to teachers and schools 'you work out how students should progress in their learning'. One might interpret this as a significant change of strategy towards curriculum development or a statement of low level of interest in the learning outcomes. There appears to be plenty of scope for hope that it is more the former than the latter.

\section{Framing Citizenship and Enterprise Education}

Citizenship was introduced to UK schools in 2002 as a result of Education for Citizenship and the teaching of democracy in schools, the report of the Advisory Committee on Citizenship (QCA, 1998). The report was broadly accepted by the government and programmes of study were developed for both primary and secondary schools. The subject is statutory in secondary schools but not in primary schools. Its aim is as follows: 'Citizenship Education equips children and young people with the knowledge, understanding and skills to play an active part in society as informed and critical citizens who are socially and morally responsible. It aims to give them the confidence and conviction that they can act with others, have influence and make a difference in their communities.' (QCA, 2002) 
The subject is taught in a variety of ways in schools. Some schools have discrete lessons whilst others integrate it into other subjects and in some cases the two strategies are combined. A GCSE in Citizenship is available and so the subject may be assessed like any other subject. Ofsted, the schools' inspectorate, have reported on standards in the teaching of the subject. On the first occasion it reported poor standards but subsequent reports have found steady improvements, with $75 \%$ of schools graded as satisfactory in the 2006 report, Towards Consensus (Ofsted, 2006). Standards tend to be higher in schools which run the GCSE course and the situation can be readily explained. The subject is a new one and there are relatively few specialist teachers. In the past four years teachers have developed an understanding of the subject and its teaching style, which is different from many other curriculum subjects (Wales \& Clarke, 2005). PGCE courses and specialised CPD [3] are now available and so increasing numbers of teachers have now been trained. In the English examinations-focused system, the GCSE course gives the subject status and it is then taken seriously by both teachers and students as it contributes to a school's position in the educational league tables. The uptake of the GCSE course has grown significantly; from a standing start in 2003, entries reached 38,000 in 2005 and 53,607 in 2006.

We discuss Citizenship Education in an English context; it is beyond the scope of this paper to offer detailed comparison with other countries. While most curriculum subjects differ from country to country, this is especially so with Citizenship. Differences include the status of the subject; Citizenship Education may be statutory, optional or even nonexistent. Content may be political, factual or topical. Citizenship Education may also be labelled differently, for example as civics, social science, people \& society or moral education.

The aims of Citizenship Education vary enormously from country to country. In some countries, aims might include developing a sense of patriotism, making students more involved in the life of their community, helping to preserve ideals of democracy \& freedom and creating a sense of national identity.

Since 2002, the policy of encouraging secondary schools in England to become 'specialist colleges' has introduced a new status and a new set of opportunities for enterprise education. Although not included in the initial set of specialisms, 'Business and Enterprise' has become established as a popular specialism for schools: by January 2007 there were 226 such colleges, with many more applications for Business and Enterprise specialist status in the pipeline. A growing number of schools are also incorporating Citizenship into their group of specialisms. As with Citizenship, the development of qualifications, gives the subject more prominence and two qualifications are now available. One is a Business GCSE [4] (with a strong entrepreneurial theme) and the other is a level-2 qualification but in enterprise capability [5]. Such qualifications cement Enterprise as a curriculum entity.

As with Citizenship Education, we discuss Enterprise Education in an English context and it is beyond the scope of this paper to offer detailed comparison with other countries. A tension highlighted later in the paper in defining enterprise education is one between entrepreneurship and enterprise in its broad sense. While intra-country contradictions still exist, it is interesting to note that the majority of the Scandinavian countries, post-transition Eastern European countries and the three North American countries focus on entrepreneurship studies, while Scotland, England, New Zealand and Australia have embraced enterprise in terms of a 'can-do' attitude and learning in an 'enterprising way'. 


\section{A pedagogy for Citizenship in England}

Citizenship Education has been developed around three strands. These are social and moral responsibility, community involvement and political literacy. The programmes of study also have three aspects. They incorporate knowledge and understanding, skills and participation. The combination of skills and participation leads to a different style of pedagogy from many other curriculum subjects. There are few right answers in citizenship so students have to learn to evaluate points of view and develop the skill of putting themselves in other people's shoes. The approach in the Citizenship classroom is therefore considerably different from subjects in which students are in search of a single 'right' answer.

The pedagogy involves reflection-in-action (Schon, 1983) and a thoughtful approach from teachers. This requires some systematic use of evidence about students' learning and time together to explore the issues. Wales \& Clarke (2005) aver that the following factors contribute to this

- Sharing an interest in citizenship activities and their consequences for the school community.

- Being open-minded, responsible, and whole-hearted (Dewey, 1961) about citizenship.

- Recognising the value of reviewing their own practice, using evidence from classroom enquiry and other research.

- $\quad$ Enjoying collaborative dialogue with teaching colleagues.

- Looking for creativity in the development of teaching and learning strategies for citizenship.

This approach leads to teaching which helps to develop learning strategies that help students to achieve the objective of seeing the world in different ways (Marton, 1981). Citizenship students may well need to be able to recall knowledge but they require a different style of learning if they are to be able to make sense of reporting on major issues of the moment. Active learning facilitates the development of a mind set which assists the development of such attributes. Kolb's (1984) learning cycle of doing, reviewing, learning and applying, demonstrates how such an approach engages students, encourages reflection, helps them extract meaning and helps them to apply their learning to future thoughts and deeds.

In traditional subjects, attainment is expressed and measured in terms of academic achievement. It is a problem of the English system that many students develop low selfesteem because they are perceived to 'fail' to achieve in their schooling. The active element of citizenship engages students across the full ability range, to the extent that some post -16 colleges use it as a focus for students who have failed at school and need motivation. It is also popular in pupil-referral units where disruptive students are helped to develop so that they can be re-integrated into main stream schooling.

There is a small but growing body of evidence that shows that schools which take participation through citizenship seriously find that attainment rises (Hanham, 2003). Participation leads to a sense of ownership as students realise that their voices are heard and that they can make a difference. The knock-on effect appears to be an enhanced sense of belonging which leads to greater security, raised self esteem and better results. Learning about democracy through democratic experiences appears to add value throughout education. 


\section{Enterprise education: definitions and implications}

Enterprise education is a somewhat slippery concept, however, Davies and Brant (2006) categorise three broad types of definition. One sees enterprise as teaching entrepreneurship. Another sees it as more generic project development, and a final conceptualisation is the development of personal 'enterprising' dispositions, such as creativity, problem solving, and flexibility. These three definitions have drastically different implications for teaching and the organisation of the curriculum. If the purpose of enterprise education is to prepare students to start or manage businesses, then enterprise education ought to develop the knowledge, understanding and skills that are relevant for running a company or a social enterprise. In that case the link between enterprise education and business studies is close, and the appropriate type of programmes would be the familiar Young Enterprise model. However, if the purpose of enterprise education is to develop students' capacity to take the initiative in any situation, this could arguably be created in any part of the curriculum.

The latter conceptualisation highlights much of the confusion and apparent difficulty about the concept and its successful implementation. Enterprise, in this broader definition, is about something 'alive', something where outcomes are hard to predict, and something that requires an ability to cope with change and the unknown (Brant and Falk, 2007). It is therefore perhaps no surprise that the English government's approach to enterprise has none of the prescription of previous strategies such as literacy or numeracy.

So, for schools, what is enterprise education? We would suggest that there confusion arises because the literature refers to two different concepts: enterprise and entrepreneurship. Our experience of visiting schools leads us to the following observations as to what this often means in practice. Firstly, the educational culture is that teachers do what they can, so if, for example, the school becomes an enterprise specialist school, they want to do things properly and they take the transformation seriously. But they quickly discover that, unlike other areas or subjects, they have to write the rules themselves. This has two results: on the one hand, it does release energy and shifts power away from a centrally dictated curriculum, so in a real sense it does encourage teachers to become more enterprising themselves. On the other hand, once released, they then tend to assume that Enterprise is really entrepreneurship and so they come up with projects that are essentially classic entrepreneurial activities - such as small business start-ups, Christmas fairs, and raising money for charities. (Brant and Falk, 2007).

While this appears to fit, then, two of our definitions (entrepreneurship and project development) the difficulty remains over where and how to articulate and evaluate those elusive 'enterprising attributes'. This is compounded by the suspicion that these so called enterprising attributes may not of course be something new at all. Perhaps they are just what we would expect to find in definitions of good teaching (problem solving and teamwork for example) or perhaps they are simply alternative expressions for creativity? (Ibid).

The somewhat confusing Government approach to Enterprise Education raises some serious issues about whether schools can indeed do enterprise, and perhaps they raise a deeper question as to whether 'enterprise' really exists. However, facing these very tensions head on may be the necessary first step in developing a genuinely enterprising classroom. In such a space, not only will teaching and learning styles reflect an innovative, creative and open ended culture, but all teachers in the school will feel equally free to generate and develop their own ideas. (Ibid). 


\section{Citizenship and Enterprise Education: agents of change}

If Citizenship Education is primarily about democracy and Enterprise Education is primarily about business start-up then the two domains may be seen as competitors for limited curriculum space. It is our argument that this is not the case. We appear to be observing a developing symbiotic relationship between the two domains where a coming together of ideas may strengthen both and has the potential to enhance the quality of teaching and learning in England's Secondary classrooms.

As articulated in the above section, the broadening of the enterprise model beyond entrepreneurship, makes Enterprise Education hard to define. Whilst we would argue that there is a place in the school curriculum for entrepreneurship education, it is the broader and more elusive conceptualisation of enterprise that has synergy with the citizenship agenda and is exciting in terms of its potential impact in the secondary school classroom. Developing this in schools raises the questions highlighted in a speech by Phil Hope, the then skills minister in 2006 "Teaching enterprise is not an easy thing for teachers to do (sic)...It requires teachers to teach differently -sometimes to back off, to allow their students to take risks, and perhaps to fail a task. And it means that school leaders need to see any such failure not as a failure on the part of the teacher, but as part of the student's development" (Delbridge-Smith, 2006).

Essentially, according to another part of the above speech, "It is about persuading schools themselves of the value of enterprise education. We are not making them follow some prescriptive guidance We aim to create a new 'effective demand'... when schools want enterprise because they believe it's the right thing to do." (Ibid).

In the current educational climate, of data driven achievement and league tables, schools, however, feel themselves to have too little flexibility to do what they may believe is right. Perhaps Citizenship and Enterprise education might offer the framework of reference to recognise attributes and attitudes such as creating and implementing new ideas, handling uncertainty and responding positively to change. Might Citizenship and Enterprise Education be now viewed as bedfellows for change and be the long-awaited antidote to the National Curriculum? It is our argument that teaching and learning will improve if teachers are allowed to be more creative in their classrooms. We will now explore how this might be the case.

Brant (2006, pp27-28) explains there exist potentially antagonistic forces in the work place: "The creative force encourages people to be innovative and exploratory in their behaviour. The entropic force encourages people to relax and to conserve energy. If one accepts the benefits of creative approaches and one accepts that all people are capable of creativity and one wishes to develop creativity in teachers and their students, then one should affect the environment to favour creativity over entropy. A teacher can do this in his or her classroom by creating a safe learning environment for his or her pupils to explore ideas. A headteacher can do this in his or her school by creating an ethos that is supportive of creativity and ultimately the government can do this through recommendations emanating from the DfES and other public bodies, appropriate educational legislation and an inspection regime which reports on and recommends good practice."

Wales \& Clarke (2005) present 'investigation' in Citizenship Education as being a parallel to creativity and innovation, facilitating the acquisition of attitudes that facilitate innovation. "When students leave school, they need to put into practice the skills and knowledge that they have acquired during Citizenship lessons. Voting, shopping or looking for a job requires investigative skills and the use of knowledge to make sense of very different kinds of information. Investigation in school not only helps students to develop these skills but can also capture their imagination. It has specific advantages in managing 
information and perspectives, learning and transferring skills and helping students to become independent learners"

Cropley (2001) suggests that teaching methods are very important and he adds that discovery learning may be more effective than traditional pedagogy. He argues that there may be further motivational benefits from such a teaching approach resulting in a more positive attitude to school and to self. He argues that there is a key role for the teacher when devising student-centred activities, as a facilitator and as a planner. Crème (2003) explores the concept of 'playing', an example of which in a classroom context could be role-play. She argues that normally students seem to spend too much energy in 'getting it right' for fear of failure or ridicule. In a role-play scenario the students are not afraid to be creative for they find themselves in an 'intermediate area' between the subjective and objective world. The learner and learnt are separate and autonomous yet at the same time interconnected.

Theoretical perspectives and practical insights, according to Loi \& Dillon (2006), offer a conceptualization of adaptive educational environments as creative spaces; these foster certain intellectual abilities associated with creativity, notably transference and synthesis in cross-disciplinary situations. When educational environments are modelled as systems, mechanisms that maintain stability or lead to change in the system can be described. Educational systems in stasis may be good for promoting some kinds of learning, but not so good for promoting intellectual abilities associated with creativity.

\section{The new curriculum}

The curriculum in England is under revision. Its whole structure is up for debate. There is a drive to involve students in a matrix of learning experiences combined with a mix of different approaches to learning as identified below. There is evidence that young people fail to make connections between curriculum subjects according to Loi \& Dillon (2006). Creativity has been identified as an ability which grows from a range of experiences which assist them to see the connections between different subject areas.

We aver that one of the greatest barriers to creativity in English classrooms and enterprising teaching and learning is the system of school league tables and a "name and shame' culture of English government agencies. This promotes (all be it implicitly) 'defensive' teaching. There is a lot of good teaching in English classrooms, but it could be excellent teaching if teachers and pupils were willing to take greater risks. The question is whether teachers are willing to break the shackles of and over-prescriptive and constraining National Curriculum and indeed whether headteachers will let them. Will teachers continue to 'teach to the test' in the false belief that their students will do better in their examinations rather than to pursue genuine deep learning in their classrooms? While most teachers will probably continue to teach in a predominantly didactic way, we are optimistic that Citizenship and Enterprise Education offer hope of genuine education that is both of interest and relevance to students.

The Qualifications and Curriculum Authority (2007) in England suggest a range of learning experiences for students: specialised learning where young people experience the power and the passion of expert subject teaching; themed learning where young people experience learning that makes links across and beyond subjects, applying skills in relevant contexts; student-initiated learning where young people are able to contribute and pursue their own ideas and interests; and learning to learn where young people are coached and mentored to help them reflect on their own learning. This would include helping them understand how they learn, set targets and overcome barriers to build their capacity to learn in the future. 
This range of learning experiences offers the potential to restructure the school week in order to give students opportunities to develop the skills which lead to the development of creativity without losing the 'power and the passion' that can be experienced through expert subject teaching. New programmes need to be developed with care to make the most of the possible combinations and outcomes. Continuing professional development will be necessary as many teachers fear that themed learning will lead to the loss of their specialist expertise.

The Qualification and Curriculum Authority (2007) in England also suggests some approaches to learning such as active learning where young people are actively engaged in practical tasks; problem-based learning where young people are presented with problems to solve; and enquiry-based learning- where young people are encouraged to investigate and find out for themselves.

These approaches to learning can be present in any of the learning experiences. They all feature in the development of the knowledge and skills of citizenship and enterprise (Wales \& Clarke, 2005 and Davies \& Brant, 2006). This participative, democratic approach to learning helps students to develop a sense of belonging and ownership. Reflection-in-action (Schon, 1983) is very much a part of this construct as the approaches require students to explore issues together.

Themed learning provides opportunities for the pedagogical approaches that are common to citizenship and enterprise to become embedded in the curriculum. There are few themes that would not benefit from benefit from aspects of the knowledge, understanding, skills and attributes that are developed through this active, participative pedagogy. By working with teachers of other subjects in this context, there are opportunities to disseminate the approaches to learning which are prevalent in citizenship and enterprise education. Developing thematic learning incorporating active, enquiry based and problem solving learning can demonstrate the motivational effect and enhanced attainment that can result from these strategies.

If learning experiences are built around these approaches it encourages students to work collaboratively within and beyond the school. The strategies can also be used to develop students' skills in independent study. When developing such learning activities, a clear sense of audience and purpose should be built into all learning activities to make them relevant to the learner.

\section{Conclusion}

In order to succeed in life, students need a number of key skills: initiative, resourcefulness, problem solving ability - in other words they need to be enterprising. It is our argument that classroom culture in England should change and we should move from a predominantly content-driven, teacher-centred pedagogy to a more 'enterprising' pedagogy. A more democratic classroom where students are required to be proactive in their learning and where they make decisions about their own learning should lead to deeper understanding because the students are more motivated and engaged in their work. Furthermore such an approach should help develop higher-order skills of analysis, synthesis and evaluation which will equip the students to perform better in their various subject examinations.

For many students enterprise activities happen on an ad hoc basis on 'enterprise days' but this is missing the point. It is our argument that enterprise should be embedded in all classroom activities. Citizenship education, on the other hand, can also be reduced to a learning of the specified knowledge but this too misses the point. Citizenship without the development of the skills of participation is not Citizenship. Effective Enterprise education, 
combined with effective Citizenship, has the potential to develop creativity, confidence, negotiation skills, problem solving skills and initiative in our students.

\section{Correspondence}

Any correspondence should be directed to Dr Jacek Brant (E-mail: J.Brant@ioe.ac.uk), Institute of Education, University of London, 20 Bedford Way, London, WC1H 0AL, UK.

\section{Notes}

[1] We refer to the 'English' rather than British education system deliberately; the Scottish system is very different and the Welsh and Northern Irish systems are developing their own identity.

[2] Her Majesty's Inspectorate (of schools)

[3] Continuing professional development - courses for teachers that are typically offered both face-to-face and on-line.

[4] Edexcel Applied Business (Piloted 2006-07)

[5] NCFE level 2 certificate for developing enterprise capabilities

\section{References}

Brant, J. (2006) Developing subject knowledge and creativity in business and economics teachers MST Institute of Education, University of London

Brant, J and Falk, A (2007) Teaching enterprise or enterprising teachers? Learning for Life Issue $6 \mathrm{p} 4$

Creme, P. (2003) Why can't we allow students to be more creative Teaching in Higher Education, Issue 8, pp273-277.

Cropley, A. (2001) Creativity in Education and Learning Kogan Page, London.

Davies, P. and Brant, J. (2006) Business, Economics and Enterprise Routledge, London.

Davies, H. (2002) Enterprise and the economy in education (London:HMSO).

Delbridge-Smith, P (2006) Centrelink, The Schools Enterprise Education Network Centre for Education and Industry, Warwick University

Department for Education and Skills (2004) Enterprise Britain: A Modern Approach to meeting the Enterprise Challenge, London: Department for Education and Skills. Online. Available: http://www.dfes.gov.uk/ebnet/DR/DR.cfm accessed 02.04.07.

Dewey, J (1938) Experience and Education New York: MacMillan

Dewey, J (1916) Democracy in Education, New York, Macmillan

Hanham. D (2003) Participation for all students - the crucial ingredient for success, Teaching Citizenship , 5, London, Association for Citizenship Teaching.

Kolb. D. A. (1984) Experiential Learning: Experience as the Source of Learning and Development, Englewood Cliffs, NJ: Prentice Hall

Loi, D. and Dillon, P. (2006) Adaptive educational environments as creative spaces Cambridge Journal of Education, 36, pp363 - 381.

Marton, (1981) Describing conceptions of the world around us. Instructional Journal vol 10, Dortrecht, The Netherlands: Klumer

Ofsted (2006) Towards Consensus, London, Ofsted

Qualifications and Curriculum Authority (1998) Education for citizenship and the teaching of democracy in schools, Advisory Committee on Citizenship, London. http://www.qca.org.uk/downloads/6123_crick_report_1998.pdf (accessed 20.05.07)

Qualification and Curriculum Authority (2007) http://www.qca.org.uk/secondarycurriculumreview/organising/teachinglearning/index.htm (accessed 20.05.07) 
Schon, D.A (1983) The Reflective Practitioner: How practitioners think in action, London: Temple Smith

Van den Broek, A. and Heunks, F. (1993) Political Culture. Patterns of Political Orientations and Behaviour, in P. Ester, L. Halman and R. de Moor (eds. Individualizing Society: Value Change in Europe and North America, Tilburg: Tilburg University Press.

Wales, J. and Clarke, P. (2005) Learning Citizenship: practical teaching strategies for secondary schools Routledge Falmer. 